TONIOLO, Aline Dip; RIVAROLA, Claudia. A educação ambiental como força transformadora na proteção ambiental: políticas de controle sobre os Resíduos Sólidos. Revista Eletrônica Direito e Política, Programa de Pós-Graduação Stricto Sensu em Ciência Jurídica da UNIVALI, Itajaí, v.10, n.1, edição especial de 2015. Disponível em: www.univali.br/direitoepolitica - ISSN 1980-7791.

\title{
A EDUCAÇÃO AMBIENTAL COMO FORÇA TRANSFORMADORA NA PROTEÇÃOO AMBIENTAL: POLÍTICAS DE CONTROLE SOBRE OS RESÍDUOS SÓLIDOS
}

\author{
THE ENVIRONMENTAL EDUCATION AS MANUFACTURING STRENGTH IN \\ ENVIRONMENTAL PROTECTION: CONTROL POLICY ON WASTE SOLID
}

\author{
Aline Dip Toniolo ${ }^{1}$ \\ Claudia Rivarola ${ }^{2}$
}

SUMÁRIO: Introdução; 1. Meio Ambiente e a Tutela Ambiental; 2. O Poder Público e as Políticas de Controle sobre os Resíduos Sólidos; 3. A Educação Ambiental como forma transformadora na Proteção Ambiental; Considerações Finais; Referências.

RESUMO: O presente trabalho tem como objetivo primordial analisar como o Poder Público pode enfrentar os desafios na proteção e preservação ambiental através da educação ambiental. Dessa forma, essa pesquisa consiste em demonstrar como o Poder Público poderá encontrar através da educação ambiental, uma maneira de reestruturar o meio ambiente já afetado e evitar a destruição total da natureza. Sabe-se que se trata de um assunto polêmico, mas cotidiano em nossa sociedade e sendo assim, deve-se compreender que por ser patrimônio de todos os seres, o meio ambiente precisa estar amparado pela tutela estatal. Contudo, para que haja um controle ambiental apropriado, inclusive na destinação de diversos materiais e resíduos agressivos à natureza, faz-se necessário que o Poder Público crie políticas ambientais adequadas. Assim, inicialmente, esta pesquisa analisará o meio ambiente e a influência da modernidade nas questões ambientais, ou seja, seus aspectos ambivalentes, ainda serão verificados o meio ambiente como direito fundamental do indivíduo, além de averiguar a tutela estatal. Em seguida, será feita uma

\footnotetext{
1 Mestranda do Programa de Pós Graduação da Faculdade de Direito da Universidade de Passo Fundo. Soledade, Rio Grande do Sul, Brasil. Advogada. E-mail: alinediptoniolo@gmail.com.

2 Graduanda do Curso de Direito da Universidade Luterana do Brasil (ULBRA). Carazinho. Rio Grande do Sul. Brasil. E-mail: claudinharivarola@gmail.com.
} 
TONIOLO, Aline Dip; RIVAROLA, Claudia. A educação ambiental como força transformadora na proteção ambiental: políticas de controle sobre os Resíduos Sólidos. Revista Eletrônica Direito e Política, Programa de Pós-Graduação Stricto Sensu em Ciência Jurídica da UNIVALI, Itajaí, v.10, n.1, edição especial de 2015. Disponível em: www.univali.br/direitoepolitica - ISSN 1980-7791.

análise do papel do Poder Público em relação ao controle desses resíduos. Finalmente, no terceiro momento, verificar-se-á a educação ambiental como mecanismo protetor do meio ambiente, bem como o Princípio da Dignidade Da Pessoa Humana, e por último, quais os desafios do Poder Público na preservação e proteção do meio ambiente através da educação ambiental. Com isso, para esse estudo, elege-se o método de abordagem dedutivo, e utiliza-se de pesquisa bibliográfica como método procedimental, com a finalidade de expor que através do Poder Público atuante em relação à educação ambiental é que se consegue conscientizar os indivíduos para que protejam o meio ambiente favorecendo desta maneira as atuais e as futuras gerações.

Palavras-Chave: Educação Ambiental; Poder Público; Resíduos Sólidos.

ABSTRACT: This work has as main objective to analyze how the Government can meet the challenges in environmental protection and conservation through environmental education. Thus, this research is to demonstrate how the Government can find through environmental education, a way to restructure the environment already affected and prevent the total destruction of nature. We know that this is a controversial subject, but everyday in our society and as such, it should be understood that to be worth of all beings, the environment needs to be supported by the state supervision. However, to allow for a proper environmental controls, including the disposal of various materials and aggressive nature to waste It will be necessary that the Government create appropriate environmental policies. So, initially, this research will examine the environment and the influence of modernity on environmental issues, ie, their ambivalent aspects, still be checked the environment as a fundamental right of the individual and to verify the state tutelage. Then an analysis of the role of the government in relation to the control of such waste will be made. Finally, the third time will occur to environmental education as a protective mechanism of the environment as well as the principle of human dignity, and finally, what challenges the Government in preserving and protecting the environment through environmental education. Thus, for this study, is elected deductive method of approach, and makes use of literature as procedural method, in order to expose it through the acting Government in relation to environmental education is that if you can educate individuals to protect the environment favoring this way the current and future generations.

Key Words: Environmental Education. Government. Solid Waste.

\section{INTRODUÇÃO}

Desde os primórdios da humanidade, os indivíduos retiram da natureza tudo que necessitam para sua sobrevivência. Com o aumento populacional e a formação 
TONIOLO, Aline Dip; RIVAROLA, Claudia. A educação ambiental como força transformadora na proteção ambiental: políticas de controle sobre os Resíduos Sólidos. Revista Eletrônica Direito e Política, Programa de Pós-Graduação Stricto Sensu em Ciência Jurídica da UNIVALI, Itajaí, v.10, n.1, edição especial de 2015. Disponível em: www.univali.br/direitoepolitica - ISSN 1980-7791.

de novas tecnologias exige-se que se retire do meio ambiente o máximo de proveito, onde se produz uma imensa quantidade de resíduos e materiais sem destinação apropriada e torna-se nítida a degradação ambiental. Assim, é imprescindível que o senso de responsabilidade faça com que as pessoas busquem no amparo legal, a adequação necessária para evitar catástrofes ambientais irreparáveis.

Por sua vez, o Estado Democrático de Direito visa oferecer aos cidadãos que o compõem direitos e deveres por meio de suas normas. Dessa maneira, essa pesquisa enfoca como tema a educação ambiental e a maneira como esta influencia o Poder Público para que se enquadre em uma Política Pública voltada a proteção do meio ambiente. Nesse sentido, esse estudo visa como objetivo geral, a análise a respeito da educação ambiental e de como por meio dela o Poder Público pode intervir para preservar e proteger a natureza.

Dessa forma, essa pesquisa consiste em demonstrar como o Poder Público poderá encontrar através da educação ambiental, uma maneira de reestruturar o meio ambiente já afetado e evitar a destruição total da natureza. Sabe-se que se trata de um assunto polêmico, mas cotidiano em nossa sociedade e sendo assim, deve-se compreender que por ser patrimônio de todos os seres, o meio ambiente precisa estar amparado pela tutela estatal. Contudo, para que haja um controle ambiental apropriado, inclusive na destinação de diversos materiais e resíduos agressivos à natureza, faz-se necessário que o Poder Público crie políticas ambientais adequadas.

Com isso, para esse estudo, elege-se o método de abordagem dedutivo, e utiliza-se de pesquisa bibliográfica como método procedimental, com a finalidade de expor que através do Poder Público atuante em relação à educação ambiental é que se consegue conscientizar os indivíduos para que protejam o meio ambiente favorecendo desta maneira as atuais e as futuras gerações.

Com isso, a relevância dessa pesquisa se dá pelo fato desse tema suscitar diversas indagações a respeito de como usufruir o meio ambiente sem afetá-lo de uma forma catastrófica. Assim, essa é a questão que justifica esse trabalho, 
TONIOLO, Aline Dip; RIVAROLA, Claudia. A educação ambiental como força transformadora na proteção ambiental: políticas de controle sobre os Resíduos Sólidos. Revista Eletrônica Direito e Política, Programa de Pós-Graduação Stricto Sensu em Ciência Jurídica da UNIVALI, Itajaí, v.10, n.1, edição especial de 2015. Disponível em: www.univali.br/direitoepolitica - ISSN 1980-7791.

já que é necessário o amparo estatal, onde as leis firmem solidamente as diretrizes que deverão ser seguidas.

\section{MEIO AMBIENTE E A TUTELA AMBIENTAL}

Devido a diversos fatores, especialmente pela influência humana, o meio ambiente está em constante transformação, de modo que se verifica o surgimento de novas tecnologias com o intuito de suprir o mercado consumista. Em razão disso, é inevitável o descarte de diversos tipos de materiais e resíduos criados pela atividade humana, fazendo-se com que se busque a tutela estatal para dispor de leis e normas que amparem esse patrimônio ambiental ameaçado.

Nesse aspecto, nasce uma série de problemas ambientais, tais como a degradação do meio ambiente, que precisam ser solucionados com o auxílio da esfera estatal. Assim, a intervenção estatal ocorre justamente para evitar abusos em relação ao meio ambiente, e procura demonstrar que todo o ser humano individualmente ou coletivamente possui direitos e deveres em relação à proteção e preservação do planeta.

Sabe-se que, o meio ambiente vem sofrendo muitas transformações resultantes da modernidade. Nesse sentido, torna-se imprescindível esclarecer no que consiste a modernidade, entendimento extraído por meio de consulta em doutrinas voltadas ao assunto.

Aliás, faz-se mister distinguir modernidade e globalização, pois são dois fenômenos mundiais muito presentes no dia a dia do ser humano e que interferem em tudo que diz respeito à natureza.

No que concerne aos recursos naturais, explorados pela humanidade, entende-se que muito dessa atitude tem vinculação com a modernidade, sendo um conjunto de experiências vitais partilhado pelos seres humanos. Este conjunto de experiências é denominado como modernidade. A promessa de transformação do mundo e de si, de aventura, de poder, alegria, de crescimento, ao passo que a 
TONIOLO, Aline Dip; RIVAROLA, Claudia. A educação ambiental como força transformadora na proteção ambiental: políticas de controle sobre os Resíduos Sólidos. Revista Eletrônica Direito e Política, Programa de Pós-Graduação Stricto Sensu em Ciência Jurídica da UNIVALI, Itajaí, v.10, n.1, edição especial de 2015. Disponível em: www.univali.br/direitoepolitica - ISSN 1980-7791.

ameaça de aniquilar tudo que se tem, aquilo que se sabe, o que se é, e encontrar-se nesse ambiente, é ser moderno. A modernidade desintegra-se e renova-se, é contraditória e ao mesmo tempo ambígua ${ }^{3}$.

Com efeito, percebe-se que a modernidade engloba as mais variadas experiências, dispõe David Harvey 4 "a modernidade, por conseguinte, não apenas envolve uma implacável ruptura com todas e quaisquer condições históricas precedentes, como é caracterizada por um interminável processo de rupturas e fragmentações internas inerentes".

Por sua vez, a globalização traz consigo uma nova etapa, que é o capitalismo, no qual se destaca o modo de produção dos mercados, que se expandem mundialmente, e as proporções alcançadas pela globalização, que influenciam todos os regimes societários.

Dessa maneira, com a globalização, os mercados mundiais se desenvolveram demonstrando que a força capitalista veio interferir amplamente em todos os setores da sociedade, a contar na área econômica, política entre outras e, obviamente, também influencia na esfera ambiental ${ }^{5}$.

Atualmente, a questão ambiental é tema de suma importância, e torna-se uma preocupação global, na medida em que a natureza passa a dar indícios de que está sendo afetada de forma incontrolável, razão pela qual importa mencionar sobre a abrangência do termo meio ambiente. Primeiramente, o conceito de meio ambiente também pode ser analisado na Lei da Política Nacional do Meio Ambiente no $6.938 / 81^{6}$, da qual se entende por meio do art. 30, inciso I: "meio ambiente, o conjunto de condições, leis, influencias e interações de ordem física, química e biológica, que permite, abriga e rege a vida em todas as suas formas".

\footnotetext{
${ }^{3}$ HARVEY David. Condição Pós- Moderna. 5. ed. São Paulo: Loyola, 1992.p. 22.

${ }^{4}$ HARVEY David. Condição Pós- Moderna. p. 22.

${ }^{5}$ IANNI, Octavio. A Era do Globalismo. 5. ed. Rio de Janeiro: Civilização Brasileira, 2001. p. 11.

6 BRASIL, Vade Mecum Saraiva: obra coletiva de autoria da Editora Saraiva com a colaboração de Luiz Roberto Curia, Livia Céspedes e Juliana Nicoletti. 5. ed. atual. e ampl. São Paulo: Saraiva, 2013.p. 1395.
} 
TONIOLO, Aline Dip; RIVAROLA, Claudia. A educação ambiental como força transformadora na proteção ambiental: políticas de controle sobre os Resíduos Sólidos. Revista Eletrônica Direito e Política, Programa de Pós-Graduação Stricto Sensu em Ciência Jurídica da UNIVALI, Itajaí, v.10, n.1, edição especial de 2015. Disponível em: www.univali.br/direitoepolitica - ISSN 1980-7791.

Na Magna Carta de 1988, a Lei da Política Nacional do Meio Ambiente, foi recepcionada com algumas modificações. Assim, nota-se que no conceito de meio ambiente, a Constituição Federal de 1988 acrescentou, nesse assunto o lado social e também humano, onde o constituinte teve a pretensão de garantir a todos os indivíduos direitos essenciais, que dizem respeito à vida humana, permitindo que seja cobrada tanto da sociedade quanto do setor administrativo, a defesa ambiental?.

Prima-se com isso, um maior cuidado e controle em relação ao meio ambiente, com o intuito de assegurar que haja condições adequadas para a sobrevivência humana para as gerações que virão.

No entanto, a preocupação com o meio ambiente não é algo recente, já sendo abordada em Conferências anteriores a Constituição Federal de 1988. Como exemplo, menciona-se a Conferência internacional sobre questões ambientais realizada em Estocolmo em 1972, e a Rio 92 no Brasil ${ }^{8}$, que se percebe o quão o meio ambiente é intrínseco à natureza humana, ou seja, é algo essencial para a sobrevivência de todas as espécies, por isso, torna-se necessário redirecionar o pensamento e as atitudes em relação a esse patrimônio, e encontrar alternativas que ajudem a proteger a natureza de danos ainda maiores dos já presenciados. No entanto, as atitudes a serem tomadas devem estar amparadas pelos órgãos governamentais.

Importante salientar que, no Brasil, o meio ambiente começou a ganhar destaque com a Magna Carta Constitucional de 1988, onde em seus vários artigos destinados às questões ambientais, estão elencados os deveres que todo o cidadão brasileiro e o próprio País, possuem para com o meio ambiente.

\footnotetext{
7 ANTUNES, Paulo de Bessa. Direito ambiental. 6. ed., rev., ampl. e atual.Rio de Janeiro: Lumen Júris. 2002. p.52.

${ }^{8}$ SILVA, José Afonso da. Direito ambiental constitucional. 4. ed. rev. e atualizada. São Paulo: Malheiros, 2002._p. 58-59).
} 
TONIOLO, Aline Dip; RIVAROLA, Claudia. A educação ambiental como força transformadora na proteção ambiental: políticas de controle sobre os Resíduos Sólidos. Revista Eletrônica Direito e Política, Programa de Pós-Graduação Stricto Sensu em Ciência Jurídica da UNIVALI, Itajaí, v.10, n.1, edição especial de 2015. Disponível em: www.univali.br/direitoepolitica - ISSN 1980-7791.

Logicamente, é de responsabilidade de cada País, a criação de leis e normas que tutelem o meio ambiente, e no Estado brasileiro a questão ambiental foi discutida no evento Rio 92, onde esse acontecimento tornou-se um marco de entendimento que se prolonga ainda, para tentar consolidar uma agenda 21 local, e compreende-se como direito fundamental, de modo que deve empenharse para que seja mantida a qualidade de vida, a subsistência, além de proteger o meio ambiente ${ }^{9}$.

Contudo, zelar pela esfera ambiental exige a imposição de leis que ditem regras e conscientizem os povos em relação ao cuidado com a natureza, já tão afetada pela mão humana. Dessa maneira, todo tipo de atividade desenvolvida pelo ser humano e que se refere à natureza, deve ser feita cautelosamente, para não agredir o meio ambiente.

Em decorrência disso, com a degradação ambiental, tanto a vida humana quanto a vida animal e vegetal vêm sendo ameaçadas em todo o planeta, pois a resposta da natureza pelos danos sofridos dá-se em forma de alterações climáticas drásticas, tais como seca, furacões, enchentes entre outros, resultando em um rastro de destruição inimaginável, onde se vê a fragilidade do homem frente tamanha calamidade ${ }^{10}$.

Dessa maneira, verifica-se que devido à interferência humana na esfera ambiental, as consequências pela ausência de cuidado ao meio ambiente, propiciam resultados assustadores, e mostra-se imprescindível que aconteça uma atitude inteligente como incentivo a educação ambiental com o intuito de encontrar soluções imediatas para inibir a destruição total do planeta.

Convém ressaltar que ao longo dos anos, o meio ambiente sofre alterações pelas mais diversas razões, mas a que destaca-se é a globalização, que decorre da

\footnotetext{
${ }^{9}$ RUSCHEINSKY, Aloísio. Meio ambiente e direitos humanos: um diálogo pertinente. In Rio Grande do Sul. Assembléia Legislativa. Comissão de Cidadania e Direitos Humanos. Relatório Azul 2006: garantias e violações dos direitos humanos. Porto Alegre, CORAG: 2006. p. 79.

${ }^{10}$ AlVArenga, Paulo. Proteção jurídica do meio ambiente. São Paulo: Lemos e Cruz, 2005. p. 19-20.
} 
TONIOLO, Aline Dip; RIVAROLA, Claudia. A educação ambiental como força transformadora na proteção ambiental: políticas de controle sobre os Resíduos Sólidos. Revista Eletrônica Direito e Política, Programa de Pós-Graduação Stricto Sensu em Ciência Jurídica da UNIVALI, Itajaí, v.10, n.1, edição especial de 2015. Disponível em: www.univali.br/direitoepolitica - ISSN 1980-7791.

modernidade, onde se depara com efeitos ambivalentes, de forma a beneficiar e prejudicar a questão ambiental e a própria comunidade ${ }^{11}$.

Percebe-se, segundo Rattner ${ }^{12}$, que juntamente com a modernidade, vem a globalização que traz à tona a discussão em relação ao ser humano e as agressões por ele cometidas ao meio ambiente, e buscam-se através dos governantes, soluções mais adequadas à questão ambiental e a conscientização de toda a população mundial.

Entretanto, para ocorrer à expansão da economia mundial necessita-se de vultuosos investimentos voltados a experimentos científicos e tecnológicos, para então se chegar a resultados satisfatórios, o que reflete no meio ambiente de alguma maneira, produzindo efeitos ambivalentes que exigem atitudes voltadas à proteção ambiental.

Com a modernidade, evidenciam-se os benefícios trazidos para a humanidade, na qual o progresso veio impulsionar o crescimento econômico e social. Todavia, nota-se que não houve apenas vantagens oriundas dessa modernidade, pois ela acaba por trazer consigo diversos problemas que, inclusive, afetam de alguma maneira o próprio meio ambiente. Desse modo, Boaventura de Sousa Santos ${ }^{13}$ entende que a modernidade expressa "o projecto sócio-cultural da modernidade é um projecto muito rico, capaz de infinitas possibilidades, e como tal, muito complexo e sujeito a desenvolvimentos contraditórios".

Dessa maneira, precisa-se haver uma conscientização global no sentido de tutelar o sistema ecológico, desde investimentos de grande vulto realizados por corporações, as quais buscam na natureza subsídios para fabricação de seus materiais e produtos, bem como, das médias e pequenas empresas objetivando que o meio ambiente não seja atingido de forma irreversível.

\footnotetext{
${ }^{11}$ RATTNER, Henrique. Liderança para uma sociedade sustentável. São Paulo: Nobel, 1999. p. 86.

12 RATTNER, Henrique. Liderança para uma sociedade sustentável. p. 87.

13 SANTOS, Boaventura de Souza. A crítica da razão indolente. Para um novo senso comum: a ciência, o direito e a política de transição paradigmática. 3. ed. São Paulo: Cortez, 2001. p. 77.
} 
TONIOLO, Aline Dip; RIVAROLA, Claudia. A educação ambiental como força transformadora na proteção ambiental: políticas de controle sobre os Resíduos Sólidos. Revista Eletrônica Direito e Política, Programa de Pós-Graduação Stricto Sensu em Ciência Jurídica da UNIVALI, Itajaí, v.10, n.1, edição especial de 2015. Disponível em: www.univali.br/direitoepolitica - ISSN 1980-7791.

No entanto, se por um lado a modernidade afeta de certa forma o ecossistema, por outro, constata-se que por meio dela houve um maior crescimento econômico, a expansão dos mercados mundiais e através da rápida comunicação criada pela tecnologia, torna-se possível a troca de informações na qual o mundo capitalista está inserido, onde almeja-se melhorias nos mais variados setores.

Na realidade, constata-se que os problemas relacionados ao meio ambiente, que a princípio são de escala regional, ficam evidentes e resultam em reflexos a nível internacional. Dessa forma, há uma maior colaboração internacional a qual visa ajudar os países que estão se desenvolvendo, a enfrentar os problemas ambientais, e cumprir com as determinações em defesa do ecossistema ${ }^{14}$.

Consequentemente, se as entidades estatais investirem em políticas públicas voltadas à área educacional, o resultado será a diminuição considerável dos problemas ambientais que afetam o grupo social. Entretanto, faz-se necessário que a comunidade onde o empecilho ambiental tiver início, conjuntamente se mobilize para tentar solucionar os problemas ambientais, amparada por Políticas Públicas dirigidas para a educação ambiental, visto ser o meio ambiente um Direito Fundamental do ser humano.

Percebe-se que com esse gradativo desenvolvimento, surgem novos direitos e garantias, na qual se procura a harmonia entre as relações dos indivíduos e o meio em que estes vivem. Dessa maneira, se verifica como de primeira geração os direitos de liberdade, em seguida os sociais, descritos como de segunda geração, e, finalmente, os direitos de terceira geração, no qual se sobressai o direito ao meio ambiente ${ }^{15}$.

Frisa-se que, embora o meio ambiente esteja amparado por Leis, Normas e Princípios que norteiam sua proteção e preservação, é indispensável que o Poder

\footnotetext{
${ }^{14}$ SCHONARDIE, Elenise Felzke. Dano ambiental: omissão dos agentes públicos. Passo Fundo: UPF, 2003. p. 45.

15 FERNANDES, Márcio Borba. Termo de ajustamento de conduta ambiental e seus efeitos na responsabilização penal. In Temas Críticos em Direito. Organizadores: Alberto Wunderlich... [et al]. Guaiba: Sob Medida, 2012. v. 2. p. 62.
} 
TONIOLO, Aline Dip; RIVAROLA, Claudia. A educação ambiental como força transformadora na proteção ambiental: políticas de controle sobre os Resíduos Sólidos. Revista Eletrônica Direito e Política, Programa de Pós-Graduação Stricto Sensu em Ciência Jurídica da UNIVALI, Itajaí, v.10, n.1, edição especial de 2015. Disponível em: www.univali.br/direitoepolitica - ISSN 1980-7791.

Público fiscalize e direcione as condutas de toda a sociedade, para que as gerações que virão usufruam dos recursos ambientais do planeta.

\section{O PODER pÚblico e AS políticas de CONTROLE SObRe OS RESÍDUOS SÓLIDOS}

O Poder Público é o detentor das vias legais para impedir a agressão ao meio ambiente, razão pela qual é essencial investimentos em Políticas Públicas voltadas à proteção ambiental. Assim, essas políticas devem restringir as ações que poluem, danificam e destroem o ecossistema ambiental, por ser esse um bem que a todos pertence, para que as novas gerações possam desfrutar deste patrimônio, sem esgotá-lo totalmente.

Nesse patamar, incumbe-se ao Poder Público, não só os estudos relacionados à questão ambiental, entre os quais citam-se os impactos ocasionados ao meio ambiente, bem como verificar as atividades humanas que provocam prejuízos inconcebíveis. Além disso, deve-se estabelecer uma penalidade correspondente ao dano causado. No entanto, para que isso ocorra de maneira coerente, é necessário que haja a repartição de competências entre os Entes Federados, onde as normas que as norteiam, atribuam-lhes matérias gerais ou específicas, para que haja a possibilidade de uma administração coesa e voltada ao conforto de toda a sociedade ${ }^{16}$.

No tocante a questão ambiental no Brasil, depara-se que a Lei Maior Fundamental determina a necessidade do envolvimento do Poder Público para legislar sobre esse assunto. Desse modo, para Silva ${ }^{17}$, a Magna Carta de 1988, determina que a União, os Estados, o Distrito Federal e os Municípios, formam a República Federativa do Brasil, e cada um desses Entes Federados possui autonomia. Essa autonomia que Ihes é dada apoia-se em órgãos próprios para

\footnotetext{
${ }^{16}$ SIRVINSKAS, Luís Paulo. Manual de direito ambiental. 6. ed. rev. atual. e ampl. São Paulo: Saraiva, 2008. p. 110.

${ }^{17}$ SILVA, José Afonso da. Direito ambiental constitucional. p. 71.
} 
TONIOLO, Aline Dip; RIVAROLA, Claudia. A educação ambiental como força transformadora na proteção ambiental: políticas de controle sobre os Resíduos Sólidos. Revista Eletrônica Direito e Política, Programa de Pós-Graduação Stricto Sensu em Ciência Jurídica da UNIVALI, Itajaí, v.10, n.1, edição especial de 2015. Disponível em: www.univali.br/direitoepolitica - ISSN 1980-7791.

governar e apresenta competência exclusiva, onde esses componentes são reconhecidos pela Constituição Brasileira.

Observa-se através das palavras de Silva $^{18}$ que, na medida em que o grupo social deixa de cumprir com determinações voltadas a preservação e proteção ambiental, deve-se recorrer aos meios legais para coibir tais atitudes, e para atender ao cumprimento das medidas cabíveis, é imperioso a repartição de competências entre as Entidades da Federação, onde demonstra-se a atuação do Poder Público.

Consequentemente, para cuidar das diversas matérias legislativas, inclusive as referentes à questão ambiental, é importante que haja a repartição de competências entre os Entes Federados, já que quando se trata de Direito Ambiental, esse assunto pode tornar-se interesse tanto da União quanto dos Estados e Municípios. Dessa forma, no Brasil é empregado o Princípio da Predominância dos Interesses, na divisão de competências ${ }^{19}$.

Nota-se, porém, que apesar do Poder Público ter a incumbência de cuidar e proteger o meio ambiente, também há a obrigação de toda a sociedade mantê-lo em condições adequadas, onde pode existir o uso dos recursos ambientais, mas de forma equilibrada, para não haver a extinção desse bem maior, propriedade de todos. Unindo esforços, torna-se possível conservar o meio ambiente equilibrado, para que haja o prosseguimento de vida de diversas espécies já ameaçadas $^{20}$.

Pertinente a divisão de tarefas entre as Entidades da Federação, necessita-se encontrar um norte sólido para tutela do meio ambiente, visto que as atividades humanas podem trazer graves riscos ao ecossistema, quando não há o controle efetivo.

\footnotetext{
${ }^{18}$ SILVA, José Afonso da. Direito ambiental constitucional. p. 72.

${ }^{19}$ FIORILLO, Celso Antonio Pacheco. Curso de direito ambiental brasileiro. 9. ed. rev., atual. e ampl. São Paulo: Saraiva, 2008. p. 86.

${ }^{20}$ SIRVINSKAS, Luís Paulo. Manual de direito ambiental. p.111.
} 
TONIOLO, Aline Dip; RIVAROLA, Claudia. A educação ambiental como força transformadora na proteção ambiental: políticas de controle sobre os Resíduos Sólidos. Revista Eletrônica Direito e Política, Programa de Pós-Graduação Stricto Sensu em Ciência Jurídica da UNIVALI, Itajaí, v.10, n.1, edição especial de 2015. Disponível em: www.univali.br/direitoepolitica - ISSN 1980-7791.

Oportuno compreender que, quando a matéria a ser discutida versar sobre as questões ambientais, podem ocorrer casos em que a União deve solucionar através de sua competência o problema ocasionado, bem como, podem surgir empasses em que o Estado ou o próprio Município precisem resolver por meio da atribuição de competências que Ihes é fornecida pela Carta Constitucional de 1988.

Eis o motivo pelo qual há a repartição de competências, ou seja, é através dela que se procura encontrar a solução para os empasses que atingem o meio ambiente, até porque, quando cada ente consegue solucioná-los, prova que está a cumprir com o que determina a Constituição referente à fixação de competências.

É devido ao fato de que todo o cidadão tem por obrigação preservar e conservar o meio ambiente, que se têm na tutela jurisdicional um mecanismo de amparo para dirimir questões que envolvam esse assunto. Dessa maneira, são criadas normas específicas à questão ambiental, na tentativa de controlar a poluição e a degradação ocasionada ao ecossistema. Logo, a interferência do Poder Público mostra-se como uma ferramenta imprescindível para a efetivação do cumprimento das leis impostas. E assim, no Brasil surgem Políticas Públicas, destinadas a firmar leis ambientais, que protegem o meio ambiente.

A Lei Maior de 1988 enfatiza a questão ambiental em vários artigos, de forma direta ou indireta. No ordenamento jurídico há uma gama de leis, decretos e resoluções infraconstitucional, as quais objetivam a preservação do meio ambiente.

Dentre as leis tem-se: a Lei 6.938/81, intitulada de Lei de Política Nacional do Meio Ambiente, a Lei 9.605/98, a qual trata de crimes ambientais, infrações e sanções administrativas e a Lei $9.985 / 00$ que se refere ao sistema Nacional de Unidades de Conservação ${ }^{21}$.

\footnotetext{
21 MEDAUAR, Odete. Alcance da proteção do meio ambiente pela via jurisdicional: controle das políticas públicas ambientais? In Políticas Públicas Ambientais: estudos em homenagem ao
} 
TONIOLO, Aline Dip; RIVAROLA, Claudia. A educação ambiental como força transformadora na proteção ambiental: políticas de controle sobre os Resíduos Sólidos. Revista Eletrônica Direito e Política, Programa de Pós-Graduação Stricto Sensu em Ciência Jurídica da UNIVALI, Itajaí, v.10, n.1, edição especial de 2015. Disponível em: www.univali.br/direitoepolitica - ISSN 1980-7791.

Mas, além das Leis acima referidas, surge em dois de agosto de 2010, a Lei no $12.305^{22}$, que institui a Política Nacional dos Resíduos Sólidos, a qual vem dispor especialmente sobre esta espécie de resíduos, sendo composta de cinquenta e sete artigos, sendo todos de suma importância. Trata-se de uma Lei que abrange desde a conceituação de resíduos sólidos, estabelecendo princípios e firmando sua importância ao dispor sobre aqueles que são norteadores, entre os quais se destacam: prevenção e precaução; poluidor-pagador; desenvolvimento sustentável; a responsabilidade compartilhada pelo ciclo de vida do produto; entre outros de suma relevância.

Em suma, nota-se que a Lei de Política Nacional de Resíduos Sólidos, veio para auxiliar a proteção e preservação ambiental, além de definir cuidados essências a serem tomados em relação a esse tipo de material, que são poluentes e precisam ter destinação apropriada, para que não atinjam de forma irreparável o ecossistema ambiental. Entretanto, é imprescindível o controle e fiscalização pelo Poder Público, para que haja a obediência a este dispositivo legal.

Frisa-se que para compreensão do tema, necessário faz-se conceituar poluição, em especial, descrever o que é a poluição por resíduos sólidos, para, posteriormente, averiguar o papel do Poder Público no controle desses resíduo. Dessa maneira, no entendimento de Sirvinskas ${ }^{23}$ poluição é conceituada na Lei da Política Nacional do Meio Ambiente como:

a degradação da qualidade ambiental resultante de atividades que direta ou indiretamente: a) prejudiquem a saúde, a segurança e o bem estar da população; b) criem condição adversas às atividades sociais e econômicas; c) afetem desfavoravelmente a biota; d) afetem as condições estéticas ou sanitárias do meio ambiente; e) lancem matérias ou energia em desacordo com os padrões ambientais estabelecidos (art.30, II, da Lei n. 6.938/81).

Professor Michel Prieur / coordenação Clarissa Ferreira Macedo D'Isep, Nelson Nery Junior, Odete Medauar. São Paulo: Revista dos Tribunais, 2009. p. 219-220.

22 BRASIL. Lei no 12.305/2010. Lei de Política Nacional de Resíduos Sólidos. Disponível em:<http://www.planalto.gov.br/ccivil_03/_ato2007-2010/2010/lei//12305.htm>. Acesso em: 24. abr. 2014.

23 SIRVINSKAS, Luís Paulo. Manual de direito ambiental. 6 p. 212. 
TONIOLO, Aline Dip; RIVAROLA, Claudia. A educação ambiental como força transformadora na proteção ambiental: políticas de controle sobre os Resíduos Sólidos. Revista Eletrônica Direito e Política, Programa de Pós-Graduação Stricto Sensu em Ciência Jurídica da UNIVALI, Itajaí, v.10, n.1, edição especial de 2015. Disponível em: www.univali.br/direitoepolitica - ISSN 1980-7791.

Conforme Sirvinskas ${ }^{24}$, percebe-se que toda a atividade indireta ou direta, que possa acarretar danos ao grupo social, seja na área da segurança ou da saúde, na esfera econômica, no que diz respeito à flora e a fauna ou ao meio ambiente em si, será uma forma de poluição, quando alterar a condição natural do sistema ambiental.

Nesse contexto, mostra-se inevitável que os órgãos públicos controlem e fiscalizem as atividades do grupo social, já que o meio ambiente é um Direito Humano Fundamental e condição primordial para que todos os indivíduos tenham uma vida sadia, de modo que envolva a Saúde Pública.

Entende-se ser obrigatória a atuação dos Entes Federados na questão dos resíduos sólidos. Entretanto, no entendimento de Machado ${ }^{25}$, referente à organização dos serviços de limpeza pública, coleta, transporte e depósito, desses resíduos, há um especial interesse do Município, o qual acaba por predominar ao interesse da União e dos Estados. Porém, estes precisam contribuir financeiramente com os Municípios, já que no tratamento de determinados tipos de resíduos, deve haver uma técnica experimental mais avançada e investimentos para implantar usinas de tratamento para esses resíduos.

\section{A EDUCAÇÃO AMBIENTAL COMO FORMA TRANSFORMADORA NA PROTEÇÃO AMBIENTAL}

A questão ambiental é tema importantíssimo, e deve ser amparado pela tutela jurisdicional de todos os países do globo terrestre, já que é patrimônio humano e, é deste bem único que depende a sobrevivência de todas as espécies vivas.

Além disso, por ser o meio ambiente um direito fundamental, é reponsabilidade não apenas do Poder Público a sua conservação e proteção, antes disso, é dever

\footnotetext{
${ }^{24}$ SIRVINSKAS, Luís Paulo. Manual de direito ambiental. 6 p. 212.

25 MACHADO, Paulo Affonso Leme. Direito Ambiental Brasileiro. 11. ed. rev. atual. amp. São Paulo: Malheiros, 2003. p. 527.
} 
TONIOLO, Aline Dip; RIVAROLA, Claudia. A educação ambiental como força transformadora na proteção ambiental: políticas de controle sobre os Resíduos Sólidos. Revista Eletrônica Direito e Política, Programa de Pós-Graduação Stricto Sensu em Ciência Jurídica da UNIVALI, Itajaí, v.10, n.1, edição especial de 2015. Disponível em: www.univali.br/direitoepolitica - ISSN 1980-7791.

da sociedade em geral. A maneira mais sensata de inibir a destruição do planeta e, consequentemente de todas as espécies vivas, é através da educação para o meio ambiente.

Nesse aspecto, com a implantação de Políticas Públicas destinadas a educação ambiental, há grandes possibilidades de reduzir as agressões que afetam o meio ambiente e apontar a melhor forma de usufruir deste patrimônio, sem o temor de que esta preciosidade única, que é o ecossistema ambiental, possa esgotar-se caso as atitudes humanas não mudem, de modo a contribuir para a percepção dos seres humanos em relação a importância de zelar pela esfera ambiental.

Desse modo, Antunes ${ }^{26}$ dispõe que a educação ambiental precisa ser promovida pelo Estado, visto ser um dos mais importantes mecanismos de prevenção ao meio ambiente, expresso na Carta Maior brasileira de 1988. A educação ambiental é a forma mais viável economicamente e mais eficaz, para inibir os danos ambientais e quando implantada, este instrumento demonstra que o Princípio da Prevenção está sendo aplicado de maneira correta.

Dessa maneira, por meio da educação chega-se a uma convivência harmônica com a natureza e, verifica-se a possibilidade de utilizar-se dos recursos que esta oferece, sem extingui-los completamente. Importante ressaltar que, através da educação ambiental abre-se espaço para a conscientização de jovens e crianças, de modo a mostrar a imprescindibilidade que há em preservar e proteger o meio ambiente e buscar corrigir as atitudes dos adultos em face da questão ambiental.

Além disso, é indispensável que o grupo social se conscientize para o fato de que se não houver cuidados em torno do meio ambiente, os recursos que são fornecidos pela natureza podem tornar-se escassos. Constata-se que a educação ambiental visa conscientizar a sociedade que o consumo sustentável é uma maneira de impedir que os recursos naturais acabem, almejando incentivar os indivíduos a adoção de novos hábitos em relação ao meio ambiente.

${ }^{26}$ ANTUNES, Paulo de Bessa. Direito ambiental. p. 52. 
TONIOLO, Aline Dip; RIVAROLA, Claudia. A educação ambiental como força transformadora na proteção ambiental: políticas de controle sobre os Resíduos Sólidos. Revista Eletrônica Direito e Política, Programa de Pós-Graduação Stricto Sensu em Ciência Jurídica da UNIVALI, Itajaí, v.10, n.1, edição especial de 2015. Disponível em: www.univali.br/direitoepolitica - ISSN 1980-7791.

Obviamente que, esta mudança de hábitos deve começar no interior da residência de cada indivíduo, com atitudes simples, como as acima referidas. Entretanto, para que ocorra uma reflexão sólida de todo grupo social, de modo que respeite os bens ambientais, faz-se imprescindível a implementação de programas de educação ambiental comprometidos no sistema de ensino do País.

Percebe-se que através de políticas públicas voltadas à educação ambiental, a sociedade será incentivada a preservar e proteger o meio ambiente de uma forma responsável e, utilizará os recursos que a natureza oferece de maneira correta.

Dessa maneira, verifica-se que a educação ambiental no Brasil, vem trabalhar localmente as realidades da comunidade, interligando-as com as realidades globais, com a finalidade de transformá-las através da informação e, provando que as atitudes podem causar mudanças, se tomadas corretamente.

Em seguida, é indubitável que os cidadãos tenham condições de existência mínimas para manter-se dignamente e, para isso, busca-se amparo no Princípio da Dignidade da Pessoa Humana, o qual é incumbência dos órgãos estatais, e estes devem proteger e promover concretamente uma vida digna a todos ${ }^{27}$.

A Dignidade da Pessoa Humana é um princípio Constitucional valioso, ou seja, de alto valor jurídico. Não resta dúvida, que todas as questões que envolvem os cidadãos, seja individualmente ou coletivamente, no contexto social, precisam passar pelo crivo normativo do princípio em tela, já que no contexto jurídico constitucional, este princípio tem supremacia.

Obviamente que quando o assunto em pauta for o ser humano e sua ligação incondicional com o meio ambiente, torna-se inevitável a compreensão de que para manter dignamente a vida, é preciso que o sistema ambiental seja amparado e tutelado de todas as formas possíveis, já que este é essencial a vida de todas as espécies.

27 SARLET, Ingo Wolfgang. Dignidade da pessoa humana e direitos fundamentais na Constituição Federal de 1988. 2. ed. rev. amp. Porto Alegre: Livraria do Advogado, 2002. p. 36. 
TONIOLO, Aline Dip; RIVAROLA, Claudia. A educação ambiental como força transformadora na proteção ambiental: políticas de controle sobre os Resíduos Sólidos. Revista Eletrônica Direito e Política, Programa de Pós-Graduação Stricto Sensu em Ciência Jurídica da UNIVALI, Itajaí, v.10, n.1, edição especial de 2015. Disponível em: www.univali.br/direitoepolitica - ISSN 1980-7791.

Percebe-se que por intermédio da educação, é que a humanidade poderá entender a importância dos cuidados ambientais e, desenvolver-se de forma sustentável, a partir do momento que agir com cautela em relação ao meio ambiente, isto é, iniciar uma consciência voltada aos cuidados com o planeta.

Entretanto, sabe-se que para a implantação de mecanismos voltados aos interesses ambientais, deve haver a atuação do Estado Democrático de Direito através de Políticas Públicas. Portanto, mostra-se indispensável a presença de investimentos na área educacional, tanto no âmbito interno como externo dos países.

Desse modo, ao proporcionar educação ao grupo social, possibilita-se a mudança de pensamentos e atitudes em relação ao meio ambiente e encaminha-se ao uso sustentável da natureza.

Todavia, evidencia-se ser necessários investimentos em políticas públicas destinadas à educação ambiental. É nessa senda que Garcia ${ }^{28}$ afirma que: "sem dúvida, a nosso ver, somente a educação e as políticas públicas da educação ambiental poderão transformar mentalidades e atitudes".

Convém ressaltar que, para haver a transmissão de informações relativas ao meio ambiente, deve o Poder Público encontrar mecanismos apropriados. Nesse momento, compreende-se que a educação ambiental deve ser implantada na sociedade, como meio que visa a esclarecer os indivíduos da importância de cuidar do meio ambiente.

Assim, a educação ambiental deve ser voltada à consciência de sustentabilidade, onde os indivíduos precisam respeitar os seus semelhantes e os Estados soberanos.

${ }^{28}$ GARCIA, Maria. Educação ambiental: do "forno a lenha" às políticas públicas do meio ambiente. In Políticas públicas ambientais: estudos em homenagem ao professor Michel Prieur/ coordenação Clarissa Ferreira Macedo D'Isep, Nelson Nery Junior, Odete Nedauar. São Paulo: Revista dos Tribunais, 2009. p. 398. 
TONIOLO, Aline Dip; RIVAROLA, Claudia. A educação ambiental como força transformadora na proteção ambiental: políticas de controle sobre os Resíduos Sólidos. Revista Eletrônica Direito e Política, Programa de Pós-Graduação Stricto Sensu em Ciência Jurídica da UNIVALI, Itajaí, v.10, n.1, edição especial de 2015. Disponível em: www.univali.br/direitoepolitica - ISSN 1980-7791.

Relata-se que, por mecanismos como a educação, será possível ensinar a maneira correta de como usar os recursos naturais de forma sustentável, sem agredir indiscriminadamente a natureza, propiciando que as próximas gerações possam usufruir dessa preciosidade. Aqui, denota-se o desafio do Poder Público, ou seja, através da educação ambiental conscientizar todo o grupo social, de forma justa e ética, para os cuidados que precisam ter com o meio ambiente.

Ressalta-se, entretanto, que para transmitir adequadamente as informações destinadas à proteção e preservação do meio ambiente à sociedade, para que as atuais e futuras gerações usufruam dos recursos naturais de forma sustentável, é necessário investimentos a altos custos pelos Órgãos Públicos em diversas áreas, incluindo-se a área educacional. Contudo, observa-se que há países sem condições de arcar com os custos altos para a implantação dessas políticas.

Então, para que todos possam usufruir dos recursos fornecidos pelo ecossistema do planeta de forma sustentável, é importante que haja a equidade interna e externa dos países, na solução de problemas que envolvem as mais variadas questões, inclusive as que dizem respeito ao meio ambiente.

Eis a importância sublime da educação ambiental, da qual o Poder Público deve conceder à sociedade, ainda que isso implique em grandes investimentos, pois é somente com a educação que se alcançará o objetivo de conscientizar os indivíduos, para que haja a continuidade de vida na terra.

Constata-se com isso, que a educação para a consciência ambiental, é obrigação de todos os países, e é a melhor alternativa para preservar e proteger o meio ambiente, de maneira que, tanto as normas brasileiras, quanto as leis dos demais países, sejam aplicadas coerentemente, zelando-se pelo meio ambiente, do qual toda a humanidade depende para continuar a existir. 
TONIOLO, Aline Dip; RIVAROLA, Claudia. A educação ambiental como força transformadora na proteção ambiental: políticas de controle sobre os Resíduos Sólidos. Revista Eletrônica Direito e Política, Programa de Pós-Graduação Stricto Sensu em Ciência Jurídica da UNIVALI, Itajaí, v.10, n.1, edição especial de 2015. Disponível em: www.univali.br/direitoepolitica - ISSN 1980-7791.

\section{CONSIDERAÇÕES FINAIS}

Desde os tempos mais antigos, a natureza fornece os recursos essenciais à sobrevivência das espécies. Verificou-se que a humanidade sempre dependeu intimamente do meio ambiente para sobreviver, mas com a evolução dos tempos, o advento da modernidade e, consequentemente a globalização, trouxeram consigo, aspectos ambivalentes no tocante à questão ambiental.

A prioridade humana passa a ser focada na economia e, retiram-se da natureza todos os subsídios para fabricação de produtos postos no mercado, então consumista, não existindo uma preocupação maior com os recursos naturais.

Por ser direito fundamental de todos os indivíduos, para as presentes e vindouras gerações, o meio ambiente ecologicamente equilibrado e pertencente a todos, passou a ser tutelado pelo Pergaminho Constitucional de 1988, o qual impôs através de normas jurídicas ao Poder Público e a toda sociedade, o dever de proteger, preservar e recuperar o meio ambiente.

No estudo realizado, presenciou-se ainda, o Poder Público e as Políticas de Controle sobre os Resíduos Sólidos, onde, primeiramente, houve a análise da importância da divisão de competência dos Entes Federados e ficou demonstrado que tanto a União, Estados e Municípios, dentro dos limites fornecidos pela Lei Maior, devem atuar na preservação e proteção ao patrimônio ambiental, inclusive no que tange aos diversos tipos de materiais postos na natureza, pelo grupo social.

Outrossim, para que haja uma resolução rápida e adequada nas mais variadas questões ambientais, incluindo-se neste contexto, os resíduos sólidos diversos, depositados no meio ambiente, restou nítido que a implementação de leis nesse seguimento é de máxima relevância e, a Lei da Política Nacional de Resíduos Sólidos vem para auxiliar a proteção e preservação do meio ambiente, fazendo com que tanto os Órgãos Públicos, cada qual com sua competência ou conjuntamente, quanto a sociedade em geral, respeitem e cumpram com a legislação que Ihes é imposta. 
TONIOLO, Aline Dip; RIVAROLA, Claudia. A educação ambiental como força transformadora na proteção ambiental: políticas de controle sobre os Resíduos Sólidos. Revista Eletrônica Direito e Política, Programa de Pós-Graduação Stricto Sensu em Ciência Jurídica da UNIVALI, Itajaí, v.10, n.1, edição especial de 2015. Disponível em: www.univali.br/direitoepolitica - ISSN 1980-7791.

Analisou-se neste estudo, que todo ser humano tem direito ao meio ambiente ecologicamente equilibrado, e por ser direito fundamental, está intimamente ligado o Princípio Basilar da Dignidade da Pessoa Humana, o qual dispõe que todo o individuo deve viver com o mínimo de dignidade.

Em suma, o presente trabalho busca demonstrar que além das normas legais existentes no ordenamento jurídico brasileiro em questão ambiental, a Educação Ambiental é um mecanismo eficiente de apoio ao Poder Público, na conscientização da sociedade para a preservação, proteção e uso correto dos recursos naturais do planeta, de modo que as atuais e futuras gerações usufruam desse bem maior, respeitando-o incondicionalmente.

\section{REFERÊNCIAS DAS FONTES CITADAS}

AlvarengA, Paulo. Proteção Jurídica do Meio Ambiente. São Paulo: Lemos e Cruz, 2005.

ANTUNES, Paulo de Bessa. Direito Ambiental. 6. ed., rev., ampl. e atual.Rio de Janeiro: Lumen Júris. 2002.

BAUMAN, Zygmunt. Globalização: as consequências humanas. Tradução Marcus Penchel. Rio de Janeiro: Jorge Zahar. 1999.

BRASIL, Vade Mecum Saraiva: obra coletiva de autoria da Editora Saraiva com a colaboração de Luiz Roberto Curia, Livia Céspedes e Juliana Nicoletti. 5. ed. atual. e ampl. São Paulo: Saraiva, 2013.

\section{Lei no 12.305/2010. Lei de Política Nacional de Resíduos}

Sólidos. Disponível em:<http://www.planalto.gov.br/ccivil_03/_ato20072010/2010/lei/l12305.htm>. Acesso em: 24. abr. 2014.

BONAVIDES, Paulo. Teoria Constitucional da Democracia Participativa (Por um Direito Constitucional de luta e resistência Por uma Nova Hermenêutica Por uma repolitização da legitimidade). São Paulo: Malheiros Editores, 2001. 
TONIOLO, Aline Dip; RIVAROLA, Claudia. A educação ambiental como força transformadora na proteção ambiental: políticas de controle sobre os Resíduos Sólidos. Revista Eletrônica Direito e Política, Programa de Pós-Graduação Stricto Sensu em Ciência Jurídica da UNIVALI, Itajaí, v.10, n.1, edição especial de 2015. Disponível em: www.univali.br/direitoepolitica - ISSN 1980-7791.

FERNANDES, Márcio Borba. Termo de ajustamento de conduta ambiental e seus efeitos na responsabilização penal. In Temas Críticos em Direito. Organizadores: Alberto Wunderlich... [et al]. Guaiba: Sob Medida, 2012. v. 2

FIORILlO, Celso Antonio Pacheco. Curso de Direito Ambiental Brasileiro. 9. ed. rev., atual. e ampl. São Paulo: Saraiva, 2008.

GARCIA, Maria. Educação ambiental: do "forno a lenha" às políticas públicas do meio ambiente. In Políticas Públicas Ambientais: estudos em homenagem ao professor Michel Prieur/ coordenação Clarissa Ferreira Macedo D'Isep, Nelson Nery Junior, Odete Nedauar. São Paulo: Revista dos Tribunais, 2009.

HARVEY David. Condição Pós- Moderna. 5. ed. São Paulo: Loyola, 1992.

IANNI, Octavio. A Era do Globalismo. 5. ed. Rio de Janeiro: Civilização Brasileira, 2001.

MACHADO, Paulo Affonso Leme. Direito Ambiental Brasileiro. 11. ed. rev. atual. amp. São Paulo: Malheiros, 2003.

MEDAUAR, Odete. Alcance da proteção do meio ambiente pela via jurisdicional: controle das políticas públicas ambientais? In Políticas Públicas Ambientais: estudos em homenagem ao Professor Michel Prieur / coordenação Clarissa Ferreira Macedo D'Isep, Nelson Nery Junior, Odete Medauar. São Paulo: Revista dos Tribunais, 2009.

MORIN, Edgar, 1921. Os Sete Sabores Necessários à Educação do Futuro. Edgar Morin; tradução de Catarina Eleonora F. da Silva e Jeanne Sawaya; revisão técnica de Edgard de Assis Carvalho. 8. Ed. São Paulo: Cortez; Brasília, DF: UNESCO, 2003.

RATTNER, Henrique. Liderança para uma Sociedade Sustentável. São Paulo: Nobel, 1999.

RUSCHEINSKY, Aloísio. Meio ambiente e direitos humanos: um diálogo pertinente. In Rio Grande do Sul. Assembléia Legislativa. Comissão de Cidadania 
TONIOLO, Aline Dip; RIVAROLA, Claudia. A educação ambiental como força transformadora na proteção ambiental: políticas de controle sobre os Resíduos Sólidos. Revista Eletrônica Direito e Política, Programa de Pós-Graduação Stricto Sensu em Ciência Jurídica da UNIVALI, Itajaí, v.10, n.1, edição especial de 2015. Disponível em: www.univali.br/direitoepolitica - ISSN 1980-7791.

e Direitos Humanos. Relatório Azul 2006: garantias e violações dos direitos humanos. Porto Alegre, CORAG: 2006.

SANTOS, Boaventura de Souza. A Crítica da Razão Indolente. Para um novo senso comum: a ciência, o direito e a política de transição paradigmática. 3. ed. São Paulo: Cortez, 2001.

SARLET, Ingo Wolfgang. Dignidade da Pessoa Humana e Direitos Fundamentais na Constituição Federal de 1988. 2. ed. rev. amp. Porto Alegre: Livraria do Advogado, 2002.

SCHONARDIE, Elenise Felzke. Dano Ambiental: omissão dos agentes públicos. Passo Fundo: UPF, 2003.

Dano Ambiental: omissão dos agentes públicos. 2. ed. Passo Fundo: Universidade de Passo Fundo, 2005.

SILVA, José Afonso da. Direito Ambiental Constitucional. 4. ed. rev. e atualizada. São Paulo: Malheiros, 2002.

SIRVINSKAS, Luís Paulo. Manual de Direito Ambiental. 6. ed. rev. atual. e ampl. São Paulo: Saraiva, 2008.

Submetido em: Setembro/2014

Aprovado em: Outubro/2014 